\title{
Numerical simulation of a residential house coupled with a dual source heat pump system

\author{
R. CHARGUI, H. SAMMOUDA
}

Laboratoire d'Energie et de Matériaux (LR11ES34), Université de Sousse, ESSTHSousse, Rue Abbassi Lamine, 4011, HSousse-Tunisia

E-mail address: chargui_r@yahoo.fr, habib.sammouda@fsm.rnu.tn

\section{Keywords: Residential house; controller; Heat pump; Simulation; TRNSYS}

\begin{abstract}
With the information technology revolution and the improving requirement for indoor air environment, energy consumption for air conditioning is increasing in Tunisia. In this research, a heating a residential house using the abundant and universal sources is proposed for a residential house in Tunisia. The effect of the incidence solar radiation in the coupling of a residential house and a heat pump system in all direction of this zone during the winter has been added. The effect of ON-OFF technology in the level of the evaporator during the winter has been studied. We present a mathematical description of the house on TRNSYS, as well as the numerical results of the simulation of coupling of the several components. The incidence solar radiation, the temperature distribution and the energy consumed and delivered, and its impact on air-conditioning load in rooms have been measured using the Tunisian climate. Numerical results have been obtained for $24 \mathrm{~h}$ in January and $4500 \mathrm{~h}$ operation in winter. Results show that the system may be satisfactorily used for residential building or greenhouse heating in the Mediterranean and region of Tunisia.
\end{abstract}

\section{INTRODUCTION}

In the literature, there are many reported theoretical and experimental studies, which explain the thermal and exergetic analysis of residential house (or greenhouse) coupled with more component (solar thermosiphon collector, heat pump system, underground air tunnel system ...): A real success of solar integrated energy system requires a good solar cooling and heating system, which is in good match with the solar collector integrated on the roof or wall. Badran et al in [1] have illustrated an experimental study for an inverted trickle solar still. Badran and Jubran in [2] have developed two identical flat plate collectors of the conventional fin tube configuration. Daou et al in [3] have developed a solar cooling system with solid desiccant or liquid desiccant cooling reasonable in humid areas, in which dehumidification is considered important, or dehumidification is integrated with water evaporative cooling. Demand side management by controlling refrigerators and its effects on consumers has been studied in [4]. The above solar sorption systems have been also incorporated with a normal vapor compression cooling system to ensure the full availability of heating or cooling for buildings, or a backup heating might be used to drive solar sorption cooling system. The problems for the geometry, the thermal performance, the effect of the solar radiation, the control function and the experimental study and the numerical simulation of the heat pump system coupled with a single house using the TRNSYS software have been improved in previous work such as in ([5-16]).

The objective of this work is to model and simulate the coupling of a residential house and a heat pump system. The effects of the control function and the solar radiation in all direction of the house have been studied. Here, we present a mathematical description of the residential house on TRNSYS software, as well as the numerical results of the simulation of the residential house (type 56a on TRNSYS), such The incidence solar radiation, the temperature distribution and the energy consumed and delivered, and its impact on air-conditioning load in rooms have been measured using the Tunisian climate. 


\section{MATERIAL AND METHOD}

To simulate the combined system with residential house and heat pump, the software TRNSYS has been used. The simulations were performed in TRNSYS 16[38] during 2012. From these results new simulations have been conducted in TRNSYS 16 and a new report with the results will be available in 2013 .

\section{1. Description of the residential house on TRNSYS}

This model type (56a on TRNSYS) is useful for estimating heating or cooling loads for a residential house. Walls, windows, flat roofs, doors, and floors are included in this component. The houses consist of a ground floor, an upper floor and a loft (Fig. 1). On the ground floor there is a kitchen, a living room and a toilet. On the upper floor, there are three bedrooms with high ceilings and a toilet (Fig. 1). The main parameters of the heat pump are shown in Table 1.

\section{2. Heat pump system}

A detailed simulation study on the performance of $\mathrm{CO}_{2}$ in reversible residential heat pumps (type 20 on TRNSYS) gave quite promising results. 
Table 1. Characteristics for the residential house in TRNSYS

\begin{tabular}{|c|c|c|c|c|}
\hline Height of enclosure & Length & $\mathrm{m}$ & real & 7.5 \\
\hline Width of enclosure & Length & $\mathrm{m}$ & real & 12.0 \\
\hline Length of enclosure & Length & $\mathrm{m}$ & real & 15.0 \\
\hline $\begin{array}{l}\text { The surface number of } \\
\text { the vertical wall } \\
\text { This wall should have } \\
\text { dimensions of height } x \\
\text { width }\end{array}$ & Dimensionless & - & integer & 10 \\
\hline $\begin{array}{l}\text { The surface number of } \\
\text { the vertical wall } \\
\text { This wall should have } \\
\text { dimensions of height } x \\
\text { length }\end{array}$ & Dimensionless & - & integer & 8 \\
\hline $\begin{array}{l}\text { The surface number of } \\
\text { the vertical wall } \\
\text { This wall should have } \\
\text { dimensions of height } x \\
\text { width }\end{array}$ & Dimensionless & - & integer & 8 \\
\hline $\begin{array}{l}\text { The surface number of } \\
\text { the vertical wall } \\
\text { This wall should have } \\
\text { dimensions of height } x \\
\text { length }\end{array}$ & Dimensionless & - & integer & 8 \\
\hline Surface number of floor & Dimensionless & - & integer & 5 \\
\hline $\begin{array}{l}\text { Surface number of } \\
\text { ceiling }\end{array}$ & Dimensionless & - & integer & 6 \\
\hline $\begin{array}{l}\text { Number of windows, } \\
\text { doors on walls }\end{array}$ & Dimensionless & - & integer & 6 \\
\hline $\begin{array}{l}\text { Surface number of } \\
\text { window, door }\end{array}$ & Dimensionless & - & integer & 7 \\
\hline $\begin{array}{l}\text { Wall surface number of } \\
\text { window, door }\end{array}$ & Dimensionless & - & integer & 1 \\
\hline $\begin{array}{l}\text { Horizontal placement for } \\
\text { window, door }\end{array}$ & Length & $\mathrm{m}$ & real & 1.0 \\
\hline $\begin{array}{l}\text { Vertical placement for } \\
\text { window, door }\end{array}$ & Length & $\mathrm{m}$ & real & 1.0 \\
\hline Height of window, door & Length & $\mathrm{m}$ & real & 2.0 \\
\hline Width of window, door & Length & $\mathrm{m}$ & real & 2.0 \\
\hline
\end{tabular}


Table 2 - Main input information for the heat pump and the climatic

$\begin{array}{ccccc}\begin{array}{c}\text { Liquid source } \\ \text { temperature }\end{array} & \text { Temperature } & {\left[{ }^{\circ} \mathrm{C}\right]} & \text { real } & {[18 ; 23]} \\ \text { Flow of liquid source } & \text { Flow } & \mathrm{kg} \mathrm{h}^{-1} & \text { real } & {[200 ; 200]} \\ \text { Ambient temperature } & \text { Temperature } & {\left[{ }^{\circ} \mathrm{C}\right]} & \text { real } & {[15 ; 34]} \\ \begin{array}{c}\text { Temperature inside } \\ \text { greenhouse }\end{array} & \text { Temperature } & {\left[{ }^{\circ} \mathrm{C}\right]} & \text { real } & {[12 ; 34]} \\ \begin{array}{c}\text { Control function of the } \\ \text { pump }\end{array} & \begin{array}{c}\text { Control } \\ \text { function }\end{array} & - & \text { real } & {[1.0 ; 1.0]}\end{array}$

\subsection{Controller of the heat pump}

The controllers on TRNSYS are designed primarily for implementing temperature level control Fig. 2. Type 2 is most frequently used to control fluid flow through the heat pump loop on the basis of two Input temperatures. However, any system employing differential controllers with hysteresis can use type 2. Temperature level control in TRNSYS relies on control function, $\gamma$, which is typically constrained to $\left[\gamma_{\min }\right.$

$\left.\gamma_{\max }\right]$. Two types of temperature level control are commonly used: continuous control and discrete $(\mathrm{On} / \mathrm{Off})$ control. In continuous control, $\gamma$ can take any value from $\gamma_{\min }$ to $\gamma_{\max }$.

\section{4. Supplementary material}

\section{Mathematical Description}

In order to solve the basic equations modeling the heat transfer through and between all elements in the zone, the problem is reduced to the following matrix equation.

Where $T_{S}, i$ represents the inside surface temperature of element $i$, unless $i$ is equal to the number of surfaces plus one $(\mathrm{n}+1)$, in which case it is the zone air temperature. The factor $\mathrm{X}_{\mathrm{i}}$ includes time varying Inputs that affect $\mathrm{T}_{\mathrm{S}}, \mathrm{i} ., \mathrm{Z}_{\mathrm{i}, \mathrm{j}}$ is a coefficient relating the heat transfer between elements $\mathrm{i}$ and $\mathrm{j}$. The objective is to formulate the problem in terms of, making simplifying assumptions that result in a time independent $\mathrm{Z}_{\mathrm{i}, \mathrm{j}}$ matrix. In this manner, the $\mathrm{Z}_{\mathrm{i}, \mathrm{j}}$ matrix is inverted once at the beginning of the simulation and stored for later use. The solution of the set of equations is then reduced to multiplication of the inverted $\mathrm{Z}_{\mathrm{i}, \mathrm{j}}$ matrix and the time varying $\mathrm{X}_{\mathrm{i}}$ vector.

\section{Exterior wall}

The instantaneous heat flux entering or leaving the zone for an exterior wall can be modeled according to the following transfer function relationship.

$$
\mathscr{F}_{i}=\sum_{h=0} b_{h, i} \mathbf{T}_{s a, i, h} \quad \sum_{h=0} c_{h, i} \boldsymbol{T}_{e q, i, h} \quad \sum_{h=0} d_{h, i} \mathscr{F}_{i, h}
$$

The coefficients $\mathrm{bh}, \mathrm{ch}$, and $\mathrm{dh}$ are transfer function coefficients for current and previous values of the sol-air temperature $\left(\mathrm{T}_{\mathrm{Sa}}, \mathrm{i}\right)$, equivalent zone temperature $\left(\mathrm{T}_{\text {eq,i }}\right)$, and heat flux, $\mathrm{qi}$. A value of $h$ equal to zero represents the current time interval, $h$ equal to one is the previous hour and so on. The sol-air temperature, $\mathrm{T}_{\mathrm{sa}}, \mathrm{i}$, is the temperature of the outdoor air which, in 
the absence of all radiation exchanges, would give the same heat transfer at the outside surface as actually occurs. For a vertical wall, it is generally expressed as:

$$
T_{s a, i}=T_{a}+\frac{\left(I_{T}\right)_{i}}{h_{c, 0}}
$$

The following expression is used to evaluate the heat transfer coefficient for convection over the building:

$$
h_{c, 0}=5.7+3.8 \mathrm{~W}
$$

Where the wind speed $\mathrm{W}$ has the units of $\mathrm{ms}^{-1}$ and $\mathrm{h}_{\mathrm{c}, \mathrm{o}}$ is in

$$
\mathrm{Wm}^{-2} \mathrm{k}^{-1}
$$

The equivalent zone temperature, $\mathrm{T}_{\mathrm{eq}, \mathrm{i}}$, is analogous to a sol-air temperature for the inside surface. It is the inside air temperature, which in the absence of radiative exchange at the inside surface, gives the same heat transfer as actually occurs. This is expressed as:

$$
\mathrm{T}_{\mathrm{eq}, \mathrm{i}}=\mathrm{T}_{\mathrm{z}}+\frac{\mathrm{s}_{\mathrm{i}}+\sum_{j=1}^{N} \mathrm{~h}_{\mathrm{ij}}\left(\left|\mathrm{T}_{\mathrm{s}, \mathrm{j}}-\mathrm{T}_{\mathrm{s}, \mathrm{i}}\right|\right)}{h_{c, i}}
$$




\section{RESULTS AND DISCUSSIONS}

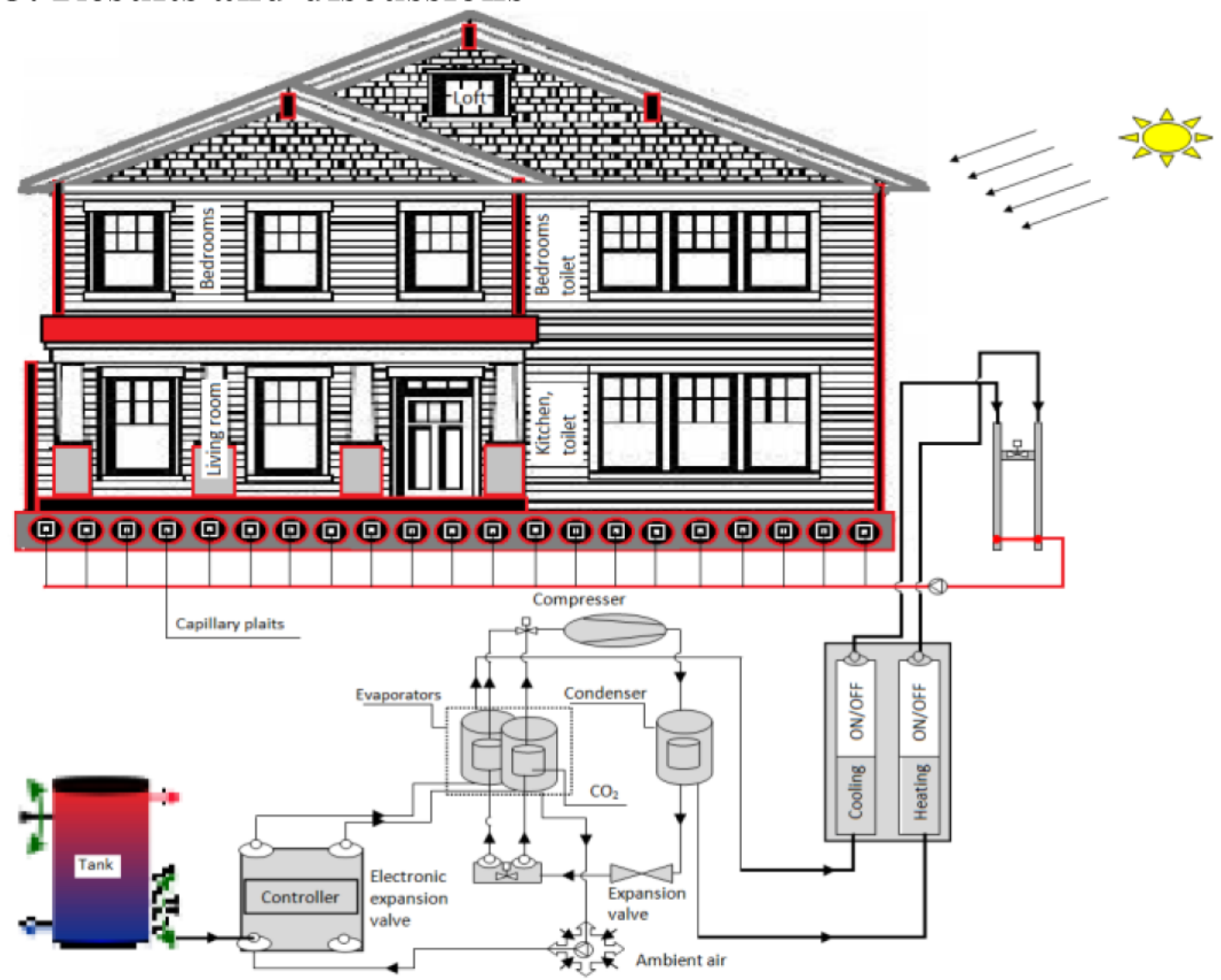

Fig. 1. Schematic of circulation system model

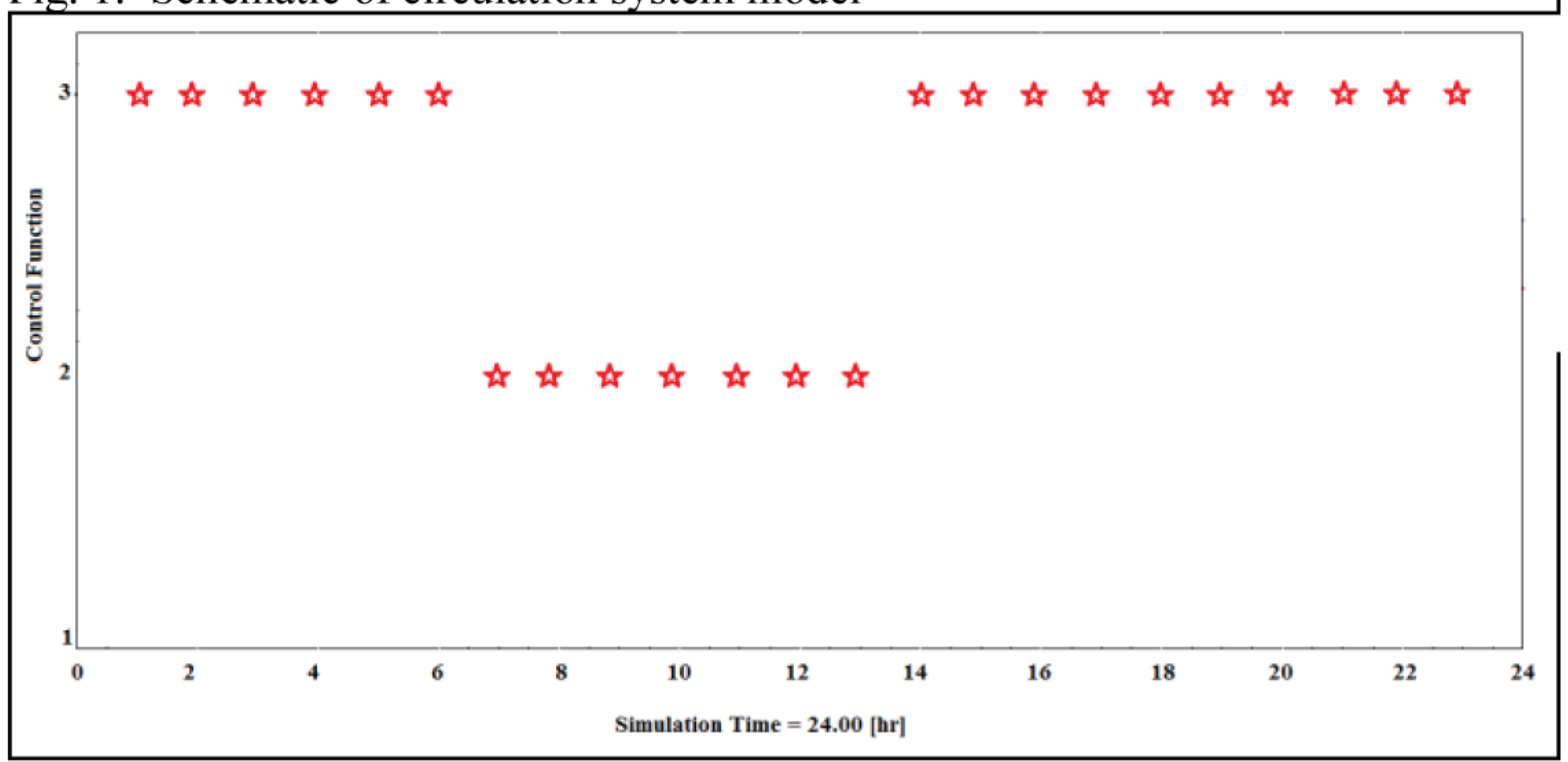

Fig. 2. Temporal evolution of a control function 


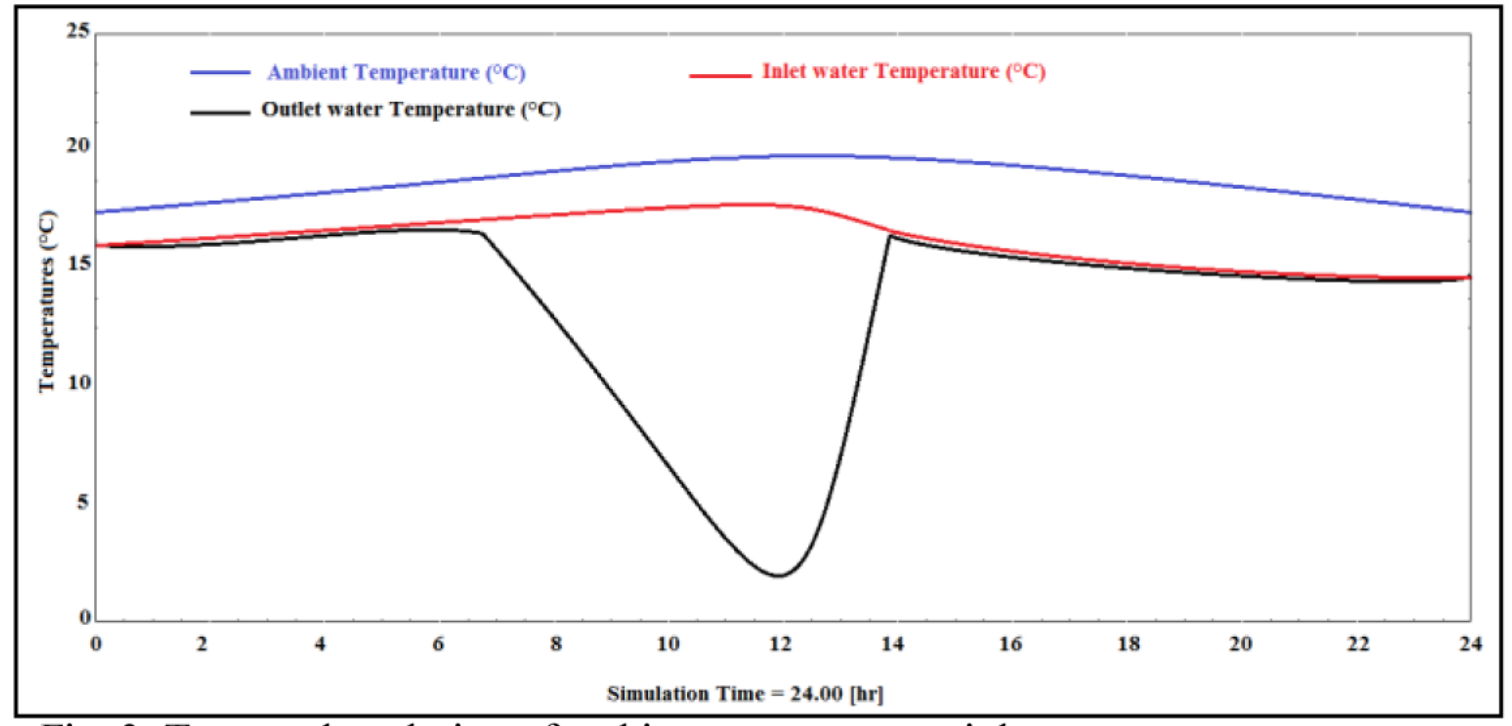

Fig. 3. Temporal evolution of ambient temperatures, inlet water temperature of the pump and outlet water temperature in the level of evaporator for $24 \mathrm{~h}$ operation in January

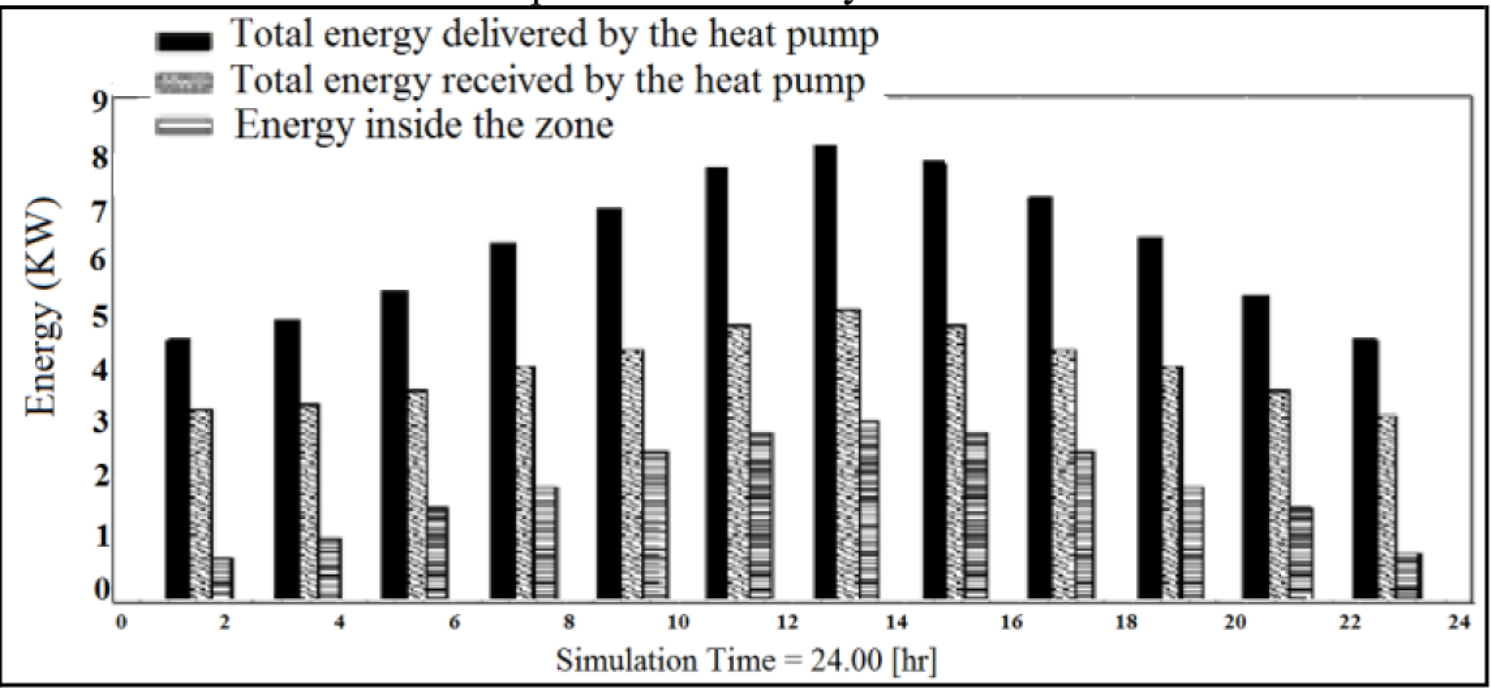

Fig. 4. Temporal evolution of Total energy received and delivered by the heat pump, the energy inside the zone for $24 \mathrm{~h}$ operation in January

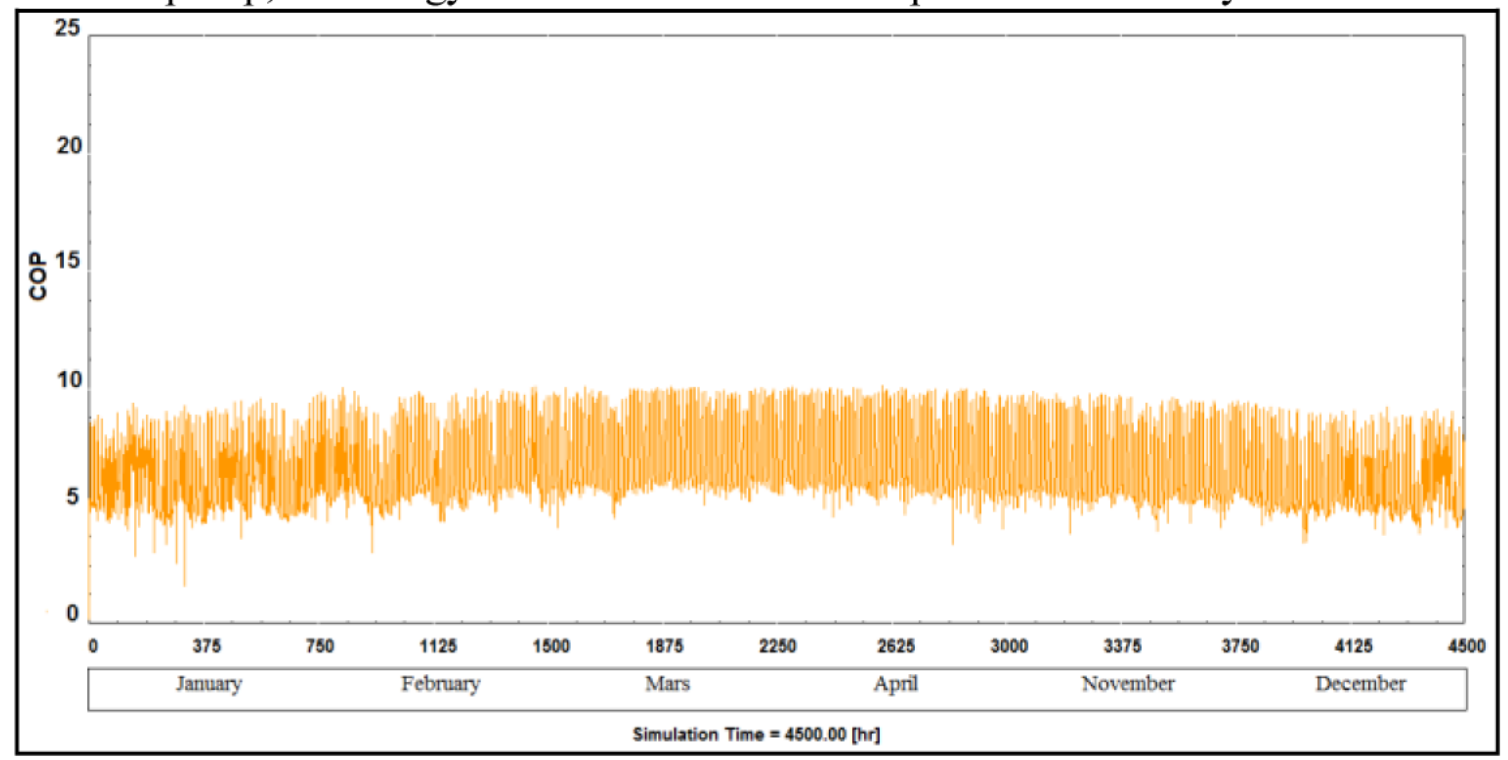

Fig. 5. COP of the heat pump in heating mode 


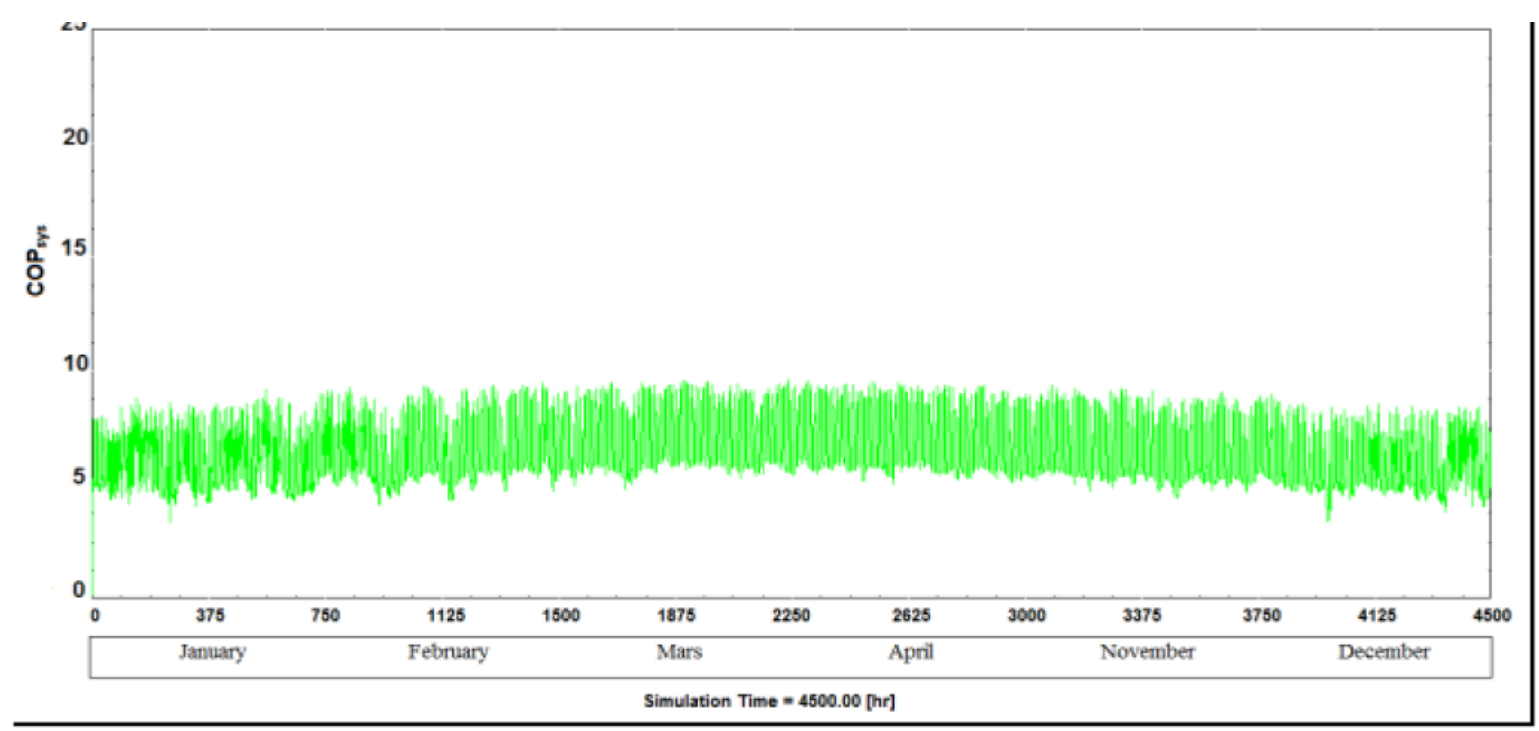

Fig. 6. $\mathrm{COP}_{\text {svs }}$ of the system in heating mode

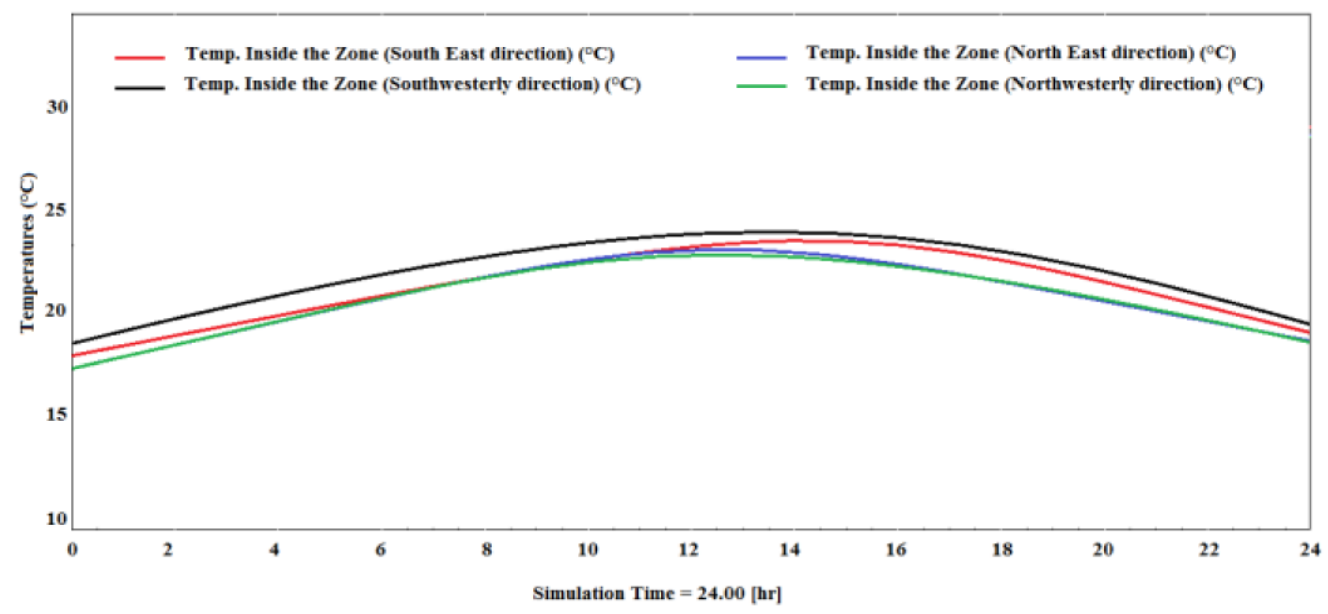

Fig.7. Temporal evolution of temperature inside the zone for $24 \mathrm{~h}$ operation in January in different direction

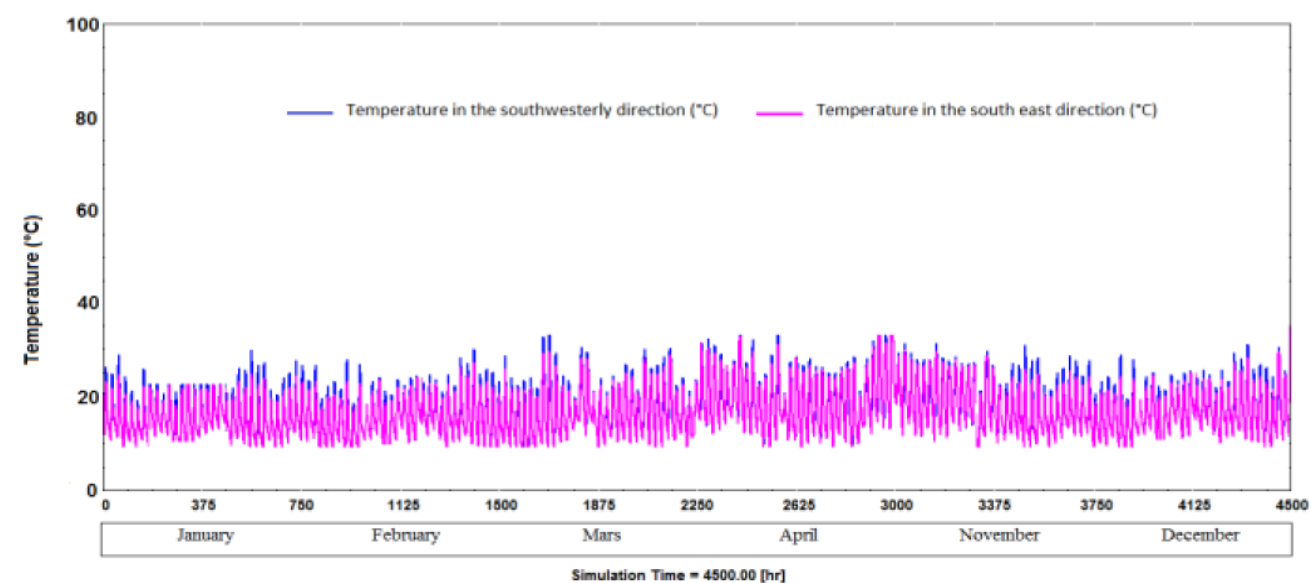

Fig.8. Temporal evolution of temperature inside the zone during heating period in the northwesterly and in the south east direction 


\subsection{Control function}

The evolution of the control function of the heat pump during the first day of January indicates a constant value equal to 0 during the first ten hours (Fig. 2). This value is explained by the fact that the heat pump works with the ambient air on the level of the cold source during this interval of time (Fig. 3). It is worth noting that this evolution announces value 1 during the remainder of the day which explains why the pump functions with the water of a liquid source on the level of the cold source.

According to the value of outlet water temperature of the tank, the controller defines the operating condition of the pump. Thus, if the temperature of water reaches its minimal value indicated by the user, controller automatically indicates the value 0 to make sure that the pump works with the ambient air on the level of the cold source (Fig. 3). If the temperature of outlet water temperature of the tank is favorable for the operating condition of the pump, the controller announces value 1(Fig. 2).

Fig. 4 show the Total energy received and delivered by the heat pump and the energy inside the zone for $24 \mathrm{~h}$ operation in January. The total energy delivered by the heat pump for one day in January increases in an appreciable way until it reaches the value 10.6 (KW), this increase is accompanied with variation of the energy received by the heat pump. Following the fall of the incidence radiation (15 to $18 \mathrm{pm}$ ), this energy decreases to be stabilized around $6.5(\mathrm{KW})$, which is also followed by decreases energy received by the heat pump and the energy inside the zone.

Figs. 5-8 show the outlet water temperature and the COP in the level of heat pump and in the level of the system, the temperature inside the zone and the total energy inside the zone for one day in January and $4500 \mathrm{~h}$ operation in winter; all

results obtained depend on the incidence solar radiation and the ambient temperature in Tunisia. The highest and the lowest values of the outlet temperature of water in heat pump and inside the zone (Figs. 5, 6-8) are obtained to be $60^{\circ} \mathrm{C}$ and $24^{\circ} \mathrm{C}$, and $20^{\circ} \mathrm{C}$ and $17^{\circ} \mathrm{C}$, respectively. The ambient air temperatures varied from 15.6 to $20^{\circ} \mathrm{C}$, the average temperatures inside the zone for $4500 \mathrm{~h}$ operation in winter are between 17.5 to $24.00^{\circ} \mathrm{C}$ (Figs. 46). The temperatures inside the zone for $24 \mathrm{~h}$ operation in January (Fig. 6) marked a maximum value in southwesterly and south east direction $\left(24{ }^{\circ} \mathrm{C}\right.$ between 10 and $16 \mathrm{~h}$; respectively $21^{\circ} \mathrm{C}$ in north east and northwesterly direction) which is explained by the influence of the solar radiation in this directions and this time.

\section{CONCLUSION}

The performance analysis and parameters on the residential house coupled with heat pump system has been carried. The simulation results of two components on TRNSYS (type 56a coupled with type 20) have been obtained. The effects of various parameters on heating mode are analyzed. The COP, the $\mathrm{COP}_{\text {sys }}$ and the outlet temperature of water on the heat pump, the energy, the temperature and the relative humidity inside the house are determined.

The COP for the heat pump and for the system can momentarily be very high in systems with water, when the temperature to the evaporator is elevated.

As systems with residential building coupled with heat pumps are very complex, it is hard to give general results or design rules. If the system is well-designed regarding heat pump capacity and building load and presuming all subsystems are working well, the best use of water during winter (November-April). The optimum periods for this control strategy depend on the size of the heat load and hot water. A careful design of the system is important in order to minimize the use of electricity. Consequently,

1. When the temperature of water increases, the COP, the COPsys, the temperatures and the energy inside the house increase also.

2. Since the temperature of water received from the tank or surface of water is higher than that of the environment, the compression rate of the compressor is rather low, by means of which it needs less energy from external sources. 
3. The performance of the heat pump was found to be between 6 and 9 for the COP, whereas the outlet water temperature was about $55^{\circ}{ }^{\circ} \mathrm{C}$. Depending on the temperature of the environment and the humidity in the house, the heat pump increased the temperature.

\section{References}

[1] Badran A A, Assaf LM, Kayed KS, Ghaith FA, Hammash M I. Simulation and experimental study for an inverted trickle solar still. Desalination 2004;164(1):77-85

[2] Badran A A, Jubran BA. Fuel oil heating by a trickle solar collector. Energy Conversion and Management. 2001;42(14):1637-1645

[3] Daou K, Wang R.Z, Xia Z.Z. Desiccant cooling air conditioning: a review. Renew. Sust. Energy Rev. 2006 ;10: 55-77.

[4] Zehir MA, Bagriyanik M. Demand side management by controlling refrigerators and its effects on consumers. Energy Convers Manage 2012;64(12):238-44.

[5] Perfumo C, Kofman E, Braslavsky JH, Ward JK. Load management: model-based control of aggregate power for populations of thermostatically controlled loads. Energy Convers Manage 2012;55(3):36-48 .

[6] Callaway DS. Tapping the energy storage potential in electric loads to deliverload following and regulation, with application to wind energy. Energy Convers Manage 2009;50(5):1389-400 .

[7] Qureshi WA, Nair NC, Farid MM. Impact of energy storage in buildings on electricity demand side management. Energy Convers Manage 2011;52(5):2110-20

[8] Rankin R, Rousseau PG. Demand side management in South Africa at industrial residence water heating systems using in line water heating methodology. Energy Convers Manage 2008;49(1):62-74

[9] Mani A, Srinivasa Murthy S. Analysis of an open type flat plate collector for tannery effluent treatment Energy Conv and Manag. 1994;35(12):1061-1071.

[10] Ekman CK, Jensen SH. Prospects for large scale electricity storage in Denmark. Energy Convers Manage 2010;51(6):1140-7.

[11] Chargui R, Sammouda H, Farhat A. Numerical simulation of a cooling tower coupled with heat pump system associated with single house using TRNSYS. Energy Conv. and Manag. 2013;75:105-117.

[12] Chargui R, Sammouda H, Farhat A. Geothermal heat pump in heating mode: Modeling and simulation on TRNSYS. Int.J.Ref. $2012 ; 35$ : 1824- 1832.

[13] Tiwari GN. Design of a Non-airconditioned Passive Solar House for the Cold Climate of Srinagar. Building and Environment 1991;96( 4):371-380.

[14] M.A. Al-Nimr. Transient behaviour of a matrix solar air heater. Energy Conv. and Manag. Volume 1993;34(8):649-656

[15] M.A. Al-nimr, M.K. Abu-qudais, M.D. Mashaqi. Dynamic behaviour of a packed bed energy storage system. Energy Conv. and Manag. 1996; 37(1): 23-30.

[16] M.A. Al-Nimr. A comparison between the steady state performance of particulate and conventional tubeless collectors. Energy Conv. and Manag 1995;36(10):1007-1014. 